\title{
O Acontecimento e a formação em Psicologia: relato de experiência em uma rede de jovens
}

\author{
Event and graduation in Psychology: an \\ experience reported in a youth network
}

\section{Samara Gonçalves da Silva Bastos' ${ }^{1}$ (D) Fábio Giorgio Santos Azevedo² (D)}

${ }^{1}$ Autora para correspondência. Escola Bahiana de Medicina e Saúde Pública (Salvador). Bahia, Brasil. samaricagoncalves@gmail.com ${ }^{2}$ Escola Bahiana de Medicina e Saúde Pública (Salvador). Bahia, Brasil. fabioazevedo@bahiana.edu.br

RESUMO | INTRODUÇÃO: O presente artigo relata a experiência, vivenciada por uma estudante do $9^{\circ}$ semestre do curso de Psicologia, através de sua inserção em uma rede de jovens. OBJETIVO: O objetivo foi analisar os efeitos da experiência para à formação em Psicologia. MÉTODO: A partir das categorias extraídas do diário de campo e com o intuito de atingir o objetivo proposto, buscou-se em literaturas cientificas voltadas para as areas da Psicologia e Educação, conceitos e noções que pudessem servir como operadores para análise da experiência. Foram escolhidos os conceitos de Experiência, Acontecimento, Saber Sensível/Conhecimento Inteligível, Saber Ético/ Saber Técnico. CONSIDERAçÕES FINAIS: Viver a experiência e refletir acerca dela, evidenciou que no decorrer do processo formativo cientificista ao qual se é submetido, só será atravessado pela experiência quem dispor o corpo para o Acontecimento. O estudo aponta também para a relevância de inserção do saber sensível na formação em Psicologia.

PALAVRAS-CHAVE: Relato de experiência. Acontecimento. Saber sensível. Formação.

\begin{abstract}
INTRODUCTION: This article reports the experience of a Psychology student, who participated in network of a youth people. OBJECTIVE: The objective was to analyze the effects of the experience for the formation in Psychology. METHOD: Categories were extracted from the field diary to fulfill the proposed objective and concepts and notions that served as operators for experience analysis were researched in scientific literature. The concepts of Experience, Event, Sensitive Knowledge/Intelligible Knowledge, Ethical Knowledge/Technical Knowledge were the chosen ones. FINAL CONSIDERATIONS: Live the experience and reflect about it evidenced that only the student who is available for Event will be crossed by the experience during the scientific formation process. The study also points to the relevance of the insertion of sensitive knowledge in the formation in Psychology.
\end{abstract}

KEYWORDS: Experience report. Event. Sensitive knowledge. Graduation. 


\section{Introdução}

A experiência que irei relatar foi fruto da interação com uma rede de jovens localizada no Bairro do Uruguai, na cidade de Salvador - BA. A inserção aconteceu a partir de um trabalho avaliativo do componente curricular Desenvolvimento do Ciclo de Vida (DCV IV) - Adolescência, que trazia em sua proposta a possibilidade dos(as) estudantes entrarem em contato com grupos que desenvolvessem trabalhos com adolescentes jovens em territórios diversificados da cidade e que utilizassem em suas ações elementos artísticos e culturais, possibilitando experiências teórico-práticas vinculadas ao campo "Saúde Mental e Juventudes".

A turma foi dividida em seis grupos e cada grupo de alunos(as) foi designado a conhecer um coletivo que desenvolvesse ações voltadas para as juventudes. A partir do contato com os coletivos, dever-se-ia caracterizar as ações desenvolvidas e articular as informações obtidas nas visitas com os conteúdos teóricos do referido componente curricular, discutindo a hipótese de que a inscrição social promovida pelas ações dos coletivos poderia ser um fator de promoção de saúde mental dos(as) jovens envolvidos(as). $O$ trabalho foi estruturado em três etapas, que foram realizadas entre fevereiro e maio do ano de 2016.

Na primeira etapa, foi realizado um levantamento de informações segundo um roteiro fornecido pelos tutores do componente curricular. Três visitas foram realizadas com o intuito de conhecer a história, a missão e os objetivos do coletivo; a localização, o território de atuação, o público envolvido; a organização administrativa, as formas de financiamento, as metodologias do trabalho, os projetos em andamento e as parcerias firmadas.

Além das informações "objetivas' que envolvem o ano de fundação, quantidade de integrantes, atividades desenvolvidas, público atendido, entre outras, os(as) alunos(as) foram orientados(as) a escrever um diário de campo, onde registrariam os efeitos subjetivos vivenciados na interação com os(as) jovens e adolescentes, além das sensações tácteis, visuais, olfativas, cinestésicas e seus significados para cada um(a), bem como as impressões e sensações envolvidas no deslocamento pela cidade e na observação estética dos lugares. O resultado dessa primeira etapa foi apresentado em forma de seminário para a turma e os professores.

Para a segunda etapa do trabalho, não havia a obrigatoriedade de novas visitas, a não ser que isso fosse uma necessidade do grupo. A proposta era que cada grupo de alunos(as) desenvolvesse uma atividade lúdico-criativa, com o objetivo de que os colegas entrassem em contato com elementos identificados nas ações desenvolvidas pelos coletivos que foram visitados.

Na terceira etapa, propôs-se que a partir do conhecimento adquirido, e levando em consideração as estratégias utilizadas pelos coletivos visitados para mediar a inscrição dos jovens no campo social, um conceito/noção trabalhado(a) nos casos do DCV-IV fosse escolhido, produzindo uma articulação teórica pertinente com as ações propostas pelo coletivo com o qual se interagiu. Foi escolhido pelo nosso grupo o conceito de identidade, e apresentamos o trabalho em forma de seminário.

Após as três visitas para realização do trabalho avaliativo do componente curricular, fui convidada a participar da rede e compor o trabalho em andamento. Passei a frequentar o coletivo uma vez por semana e a acompanhar as atividades desenvolvidas. Tendo o trabalho curricular finalizado em maio de 2016, permaneci frequentando a rede de jovens até junho de 2017.

Portanto, considerando a relevância da inserção na rede de jovens em minha formação como psicóloga, e a importância social do trabalho desenvolvido pelos(as) jovens da rede em questão, O objetivo foi analisar os efeitos da experiência para à formação em Psicologia. 
Com o intuito de atingir o objetivo proposto, foram escolhidos alguns conceitos-chave para fundamentação teórica deste trabalho. Dentre estes, estão, o conceito de experiência, a partir de Bondía (2002)'; os conceitos de anestesia, saber sensível e conhecimento inteligível, com o psicólogo Duarte Júnior (2001)². Utilizamos ainda as noções de saber ético e saber técnico, conforme as distingue Senne $(2005)^{3}$. E ainda nos servimos do conceito de acontecimento, conforme as considerações de Macedo (2016)4.

\section{Desenvolvimento}

Segundo Bondía (2002, p.21), a experiência seria "o que nos passa, o que nos acontece, o que nos toca. Não o que se passa, não o que acontece, ou o que toca", e ao passar, ao tocar, ao acontecer, formaria o sujeito, transformando-o. Entretanto, seria cada vez mais raro viver uma experiência, porque muitas coisas se passam, mas nada (ou muito pouco) acontece. Para ele, essa impossibilidade em viver uma experiência se daria por quatro fatores: o excesso de informação, o excesso de opinião, a falta de tempo e o excesso de trabalho. Tais aspectos adviriam da forma de organização da sociedade moderna capitalista que acabaria por produzir nos sujeitos uma sensação constante de insatisfação (Bondía, 2002).

Para o autor, a insatisfação constante levaria a uma frequente busca por excitação e incapacidade de viver o silêncio. Este sujeito de estímulos e vivências pontuais, se tornaria mais vulnerável ao agito, à excitação, aos atravessamentos, no entanto, nada lhe aconteceria e "por isso, a velocidade e o que ela provoca, a falta de silêncio e de memória, são também inimigas mortais da experiência" (Bondía, 2002, p.23).

Ele então conclui que viver uma experiência exigiria uma passividade e disponibilidade, quase impossível nesse tempo de correria. Exigiria parar: para pensar, parar para olhar, parar para escutar, pensar mais devagar, olhar mais devagar, e escutar mais devagar; parar para sentir, sentir mais devagar, demorar-se nos detalhes, suspender a opinião, suspender o juízo, suspender a vontade, suspender o automatismo da ação, cultivar a atenção e a delicadeza, abrir os olhos e os ouvidos, falar sobre o que nos acontece, aprender a lentidão, escutar aos outros, cultivar a arte do encontro, calar muito, ter paciência e dar-se tempo e espaço (Bondía, 2002, p.24).

Ao contrário, teríamos um sujeito incapaz de experiência, que se tornaria inacessível, inatingível, firme, apático, anestesiado.

Duarte Júnior (2001) definiria a anestesia como sendo a negação do sensível, isto é, a impossibilidade ou a incapacidade de sentir. Para o autor, o homem contemporâneo sofreria de uma anestesia que precisaria ser revertida através de uma "educação da sensibilidade" (Duarte Júnior, 2001, p.97), viabilizando a criação de uma razão mais ampla, na qual os dados sensíveis seriam levados em conta, gerando conhecimentos mais consistentes.

O autor acrescenta que o sensível seria o saber primordial detido pelo corpo humano e manifesto nas mais variadas ações, mantendo-se integro e não reduzido a simplificações cognitivas e cerebrais, visto que quem primeiro "conheceria" o mundo seria o corpo, "antes de podermos reduzi-lo a conceitos e esquemas abstratos próprios de nossos processos mentais" (Duarte Júnior, 2001, p. 126).

O saber sensível, que se faria presente na vida cotidiana através do corpo, suporia primeiramente uma vivência plena da experiência, para que, posteriormente, se pudesse pensar sobre ela, cognitivamente, a partir de um conhecimento "inteligível", compreendido pelo autor como "a capacidade de articulação abstrata, que se realizaria no cérebro, através de signos eminentemente lógicos e racionais, a exemplo das palavras, números e símbolos" (Duarte Júnior, 2001, p.127)

\footnotetext{
${ }^{1}$ Doutor em Pedagogia pela Universidade de Barcelona.

${ }^{2}$ Doutor em Filosofia da Educação pela Universidade Estadual de Campinas.

${ }^{3}$ Psicólogo e Doutor em Educação, professor na Universidade Federal da Bahia (UFBA).

${ }^{4}$ Psicólogo, Doutor em Ciências da Educação pela Universidade Paris VIII, professor na Universidade Federal da Bahia (UFBA).
} 
Relatar uma experiência seria uma possibilidade de refletir acerca dela e de sua importância para sua transformação no processo formativo. Uma experiência vivenciada no campo do sensível poderia ser analisada a partir de um conhecimento inteligível, ou seja, vivenciar uma experiência e, então, analisar os seus efeitos. Nesse contexto, levantei a hipótese de que a formação acadêmica tende a provocar o embotamento do saber sensível, tirando do corpo uma capacidade que ele já trazia, reduzindo a formação ao conhecimento inteligível, o que por vezes dificultaria o contato com determinados contextos de atuação profissional, por exemplo, o dos trabalhos ditos "comunitários".

Isso se daria porque, à medida que se avança na formação acadêmica, as técnicas de intervenção tenderiam a ocupar um lugar preponderante. Cada passo dado no campo de atuação passa ser pensado a partir das técnicas, sistematicamente ensinadas e cobradas. $O$ efeito na prática profissional seria de que as pessoas tenderiam a agir mecanicamente, esquecendo-se da "sabedoria sem palavras que mora no corpo" (Alves, 1998 apud Duarte Júnior, 2001, p.127). Nesse sentido, a experiência vivenciada no campo do saber sensível, como um saber que se obteria através da sensibilidade, e das experiências singulares de cada, seria o fundamento para os demais conhecimentos exigidos nos processos educacionais, que vêm se mostrando cada vez mais mecanicistas, objetivos e cientificistas - ainda que com reconhecidas experiências de resistência.

Contudo, o corpo, mesmo atravessado por um longo processo de negação, deteria um saber anterior aos processos, sendo, por isso, convocado a fazer experiência, a entrar em contato com o território para dele e, em certa medida, fazer parte, ao mesmo tempo em que, estrategicamente, não se estaria "colado" por completo:

paradoxalmente, este lugar do Psicólogo seria o daqueles que não tem lugar definido- ele se presta ao papel de um coringa que se posiciona ora como termo 'dentro' de uma série, multiplicidade ou nó de questão, ora como instância que, pondo-se 'de fora', mede ou descreve essa série ou esse nó (Senne, 2005, p. 233).

Desse modo, levando em conta as considerações acima, haveria que se encontrar um equilíbrio entre o saber sensível e a racionalidade, ou, como denomina Duarte Júnior (2001), o conhecimento inteligível; equilíbrio deixado de lado na modernidade ocidental. No desenvolvimento de certas habilidades em contato com a rede de jovens, foi evidenciado que a formação universitária costuma supervalorizar o intelecto em detrimento da expressividade do corpo e da sensibilidade.

Acerca do saber sensível e do conhecimento inteligível, conforme definidos por este autor, foi-nos possível identificar uma analogia pertinente entre as noções de saber ético e saber técnico, segundo Senne (2005). O saber ético seria um dispor de si mesmo, um saber que se sabe em ato, que não pode ser ensinado, mas pode ser aprendido na medida em que se permite conviver e desenvolver atividades coletivamente, como quando se é convocado a fazer em contextos de atuação comumente reconhecidos como do campo da Psicologia Comunitária. Enquanto que o saber técnico seria um saber passível de ser ensinado, que pode ser aprendido e que se adquiriria, por exemplo, a partir das práticas ofertadas na formação acadêmica.

Práticas que muitas vezes, pelo excesso de enfoque na técnica e na delimitação do "olhar", podem nunca vir a ser um acontecimento efetivamente formativo. Pois, segundo Macedo (2016), o acontecimento seria uma singularidade, um desvio que produziria escoIhas sobre uma nova maneira de ser, de atuar, de atrair. O sujeito do acontecimento, assim como o sujeito da experiência, seriam como que um território de passagem, onde se inscreveriam marcas, efeitos, que resultariam dos encontros consigo mesmo, com o outro, com o mundo.

Para o autor, o acontecimento fugiria ao previsível, como encontros não marcados que nunca deixarão de acontecer. O acontecimento, assim como a experiência, constituir-se-ia como parte integrante do corpo, e não somente em sua dimensão física. Portanto, a possibilidade de viver o acontecimento e a experiência como aspectos centrais da formação do(a) psicólogo(a), estaria diretamente relacionada à disponibilidade do corpo em acolhê-los, sendo que nem todo corpo seria um território sensível capaz de subverter o processo de negação e embotamento a que fora submetido. 


\section{O acontecer}

\section{Chegar}

"O espaço físico que a rede ocupa é aconchegante, pequeno e iluminado. Você já chega num abraço" (Diário de campo, 14 de março de 2016).

O entusiasmo inicial do primeiro semestre havia passado. Questionamentos e dúvidas sobre a escolha do curso de psicologia eram uma constante, e faltavam sentido e motivação. A graduação se mostrava um lugar inacessível, com a sensação de que o corpo não cabia nas possibilidades de atuação que se apresentavam. O desejo em deixar o curso estava cada vez mais presente. Era intenso sentimento de não pertencimento: ao curso, à instituição, à turma.

Tentei, sem sucesso, participar de ligas acadêmicas e grupos de estudos, que pareciam mais enquadrados que as atividades curriculares. Estava sendo angustiante chegar ao quarto semestre sem nenhuma perspectiva para a formação. Por outro lado, sentia medo em deixar o curso, e me perguntava que outra graduação eu poderia fazer, não sustentei resposta, para tal questionamento e por isso me mantive na graduação em Psicologia, mesmo sem encontrar nenhum sentido em estar ali.

Mas me manter implicava sofrimento: assistir aula, produzir, sem sentir motivação para isso, estava sendo algo muito difícil. E ainda um sentimento de culpa, por estar em uma instituição conceituada, ter uma oportunidade que muitos não tinham e ainda reclamar da insatisfação com o curso. Com o início do quarto semestre, a proposta diferenciada do componente curricular DCV-IV provocou em mim certo entusiasmo. A chegada à Rede de jovens, onde seria desenvolvido o trabalho curricular, e o tempo que durou a experiência, marcaram um encontro com um lugar de pertencimento acadêmico e de possível atuação profissional futura até então não vislumbrados. Este foi um Acontecimento que me fez produzir e doar sentido à minha formação.

A chegada à Rede fora atravessada: ultrapassada a distância segura que a sala de aula e os muros brancos da faculdade ofereciam, e ir ao encontro de um território conhecido pela violência cotidianamente alardeada pelas notícias na mídia, fazia-me pensar que estar ali só poderia ser muito arriscado.

Na primeira vez que fui com o grupo conhecer a rede, o medo e a tensão era tanto que o caminho passou quase todo despercebido. Na segunda ida, já mais tranquila, comecei a observar a cidade que se apresentava aos meus sentidos, e a primeira coisa que pensei: 'estou perdida, não me lembro de ter passado por aqui da outra vez'. A cada ida eu ia me soltando, me sentindo mais à vontade. Até arrisquei outros trajetos (Diário de campo, 23 de março de 2016).

Dispor o corpo à experiência, superando o receio de circular na cidade, descontruindo o olhar preconceituoso orientado pelo medo propagado nos noticiários, não foi tarefa fácil. E logo no primeiro encontro com os(as) jovens da Rede, uma fala da coordenadora pedagógica me fez despertar para o que estava em jogo no que concernia à minha formação em Psicologia:

Vocês da universidade têm que sair da universidade e ir pra rua, se não vocês nunca serão psicólogos. Esses jovens que estão aqui sabem mais que vocês, porque o dia a dia deles, é uma prática que vocês não têm. Mas como desocupar a universidade e ir para rua, se há medo em se arriscar pela cidade? E como se descolar desse fazer psicológico habitual sem circular a cidade e entrar em contato com outras possibilidades do fazer?

(Diário de campo, 19 de abril de 2016).

Analisando retrospectivamente, a proposta do componente curricular parecia começar a fazer sentido, mas antes, algumas chances de viver uma experiência foram adiadas. Porque a formação acadêmica já havia cumprido seu propósito, "entupindo" o estudante de informações, teorias e técnicas, mas toda essa parafernália impedia um contato mais próximo com as pessoas, e as relações se tornavam apenas profissionais e ser "profissional" seria, conforme certo modelo de ensino e formação do psicólogo, manter o distanciamento e a neutralidade, como apontam Nascimento, Manzini e Bocco (2006, p.15): “determinadas práticas psicológicas pautadas na neutralidade científica, onde o psicólogo não se mistura com o seu objeto, ao contrário, busca se distanciar dele, apresentando respostas cheias de certezas, acreditandose capaz de prever comportamentos". 
Na primeira visita, nosso objetivo foi levantar informações acerca da Rede. Bondía (2002) sugere que um sujeito que está todo o tempo ocupado em coIher informações, e que tem como sua maior preocupação não ter informações suficientes, acabaria contribuindo para que nada lhe acontecesse. Para o autor, o excesso de informações não possibilitaria viver uma experiência, pelo contrário, produziria uma espécie de antiexperiência: "Por isso a ênfase contemporânea na informação, em estar informados, e toda a retórica destinada a constituir-nos como sujeitos informantes e informados; a informação não faz outra coisa que cancelar nossas possibilidades de experiência." (Bondía, 2002, p.21).

Entretanto, a conversa com a coordenadora pedagógica da Rede impediu que continuássemos a anotar "dados". Os olhos nem piscavam, as mãos ficaram imóveis, e o momento foi dedicado à escuta. Foi então que compreendi que seria preciso "se abrir ao máximo para os acontecimentos que aparecem e que garantem os desvios, para o acaso dos encontros, para as associações" (Guillier, 2004, apud Nascimento, Manzini \& Bocco, 2006, p.16). Ao que parecia, só um Acontecimento - uma espécie de encontro impactante - seria capaz de possibilitar um desvio e nos descolar daquele lugar de mero coletores de informações. Foi o que aconteceu comigo.

Para concluir a coleta de informações foram necessárias outras visitas. Mas nas visitas subsequentes, o impacto da chegada já não permitia que se fosse apenas um sujeito da informação. Tudo o que foi dito pela coordenadora nos tocou de tal maneira que uma experiência a ser vivida, no sentido que the dá Bondía (2002), parecia já estar em andamento. 0 lugar já não assustava como antes, e o convite para participar da Rede, após a conclusão do trabalho curricular, provocou surpresa e contentamento, afinal, seria uma oportunidade ímpar de viver outros lugares, e aprender com outras pessoas. Parafraseando livremente Pessoa (1914/2016, p. 8): “e o que vejo a cada chegar é aquilo que nunca antes eu tinha visto, sinto-me nascida a cada chegada para a eterna novidade da rede".

\section{O Bairro e a Rede}

"A forma como se articulam dentro da comunidade e desenvolvem suas atividades é surpreendente" (Diário de campo, 12 de abril de 2016).

A rede está localizada no bairro Uruguai, um dos 14 bairros que compõem a Península de Itapagipe. Relatam moradores que o nome do bairro teria sido escolhido, em homenagem à Seleção Celeste, da Copa do Mundo de 1950. De acordo com dados do Sistema de Informação Municipal de Salvador (SIM, 2013), o bairro abriga o maior número de habitantes da Península, chegando a 30.370 pessoas. Oriundo de ocupações dos terrenos alagadiços da região, no século passado, desenvolveu-se com considerável falta de assistência do poder público.

Segundo moradores, durante a madrugada caminhões da prefeitura depositavam lixo e entulho no local, e as pessoas utilizavam esse material para fazer o aterramento do terreno alagadiço, começando a surgir as primeiras casas e palafitas da ocupação. Nos últimos anos, esse cenário vem se transformando, ainda que lentamente, resultado de luta, organização popular e reivindicação. Economicamente, o bairro do Uruguai comporta um número considerável de pequenos comércios, sendo essa talvez a principal atividade econômica.

Esteticamente, o bairro é o desenho que retrata uma típica comunidade periférica das grandes cidades brasileiras.

Fazer o tour pelo bairro foi impactante. As ruas muito estreitas e, em alguns pontos só dá para passar uma pessoa por vez. Eu só tinha visto isso em novela, não imaginei que era real, que pudesse existir. O esgoto passa pelas portas das casas e o cheiro em alguns momentos era insuportável pra mim. E imaginar que pra eles é comum, ou passa a ser, ainda que não gostem... As paredes estão pintadas, mas todas as cores estão um pouco acinzentadas. As crianças brincam alheias ao que acontece em sua volta. Durante o tour, um jovem me perguntou, como era ser turista no lugar onde ninguém quer vir morar? Eu ri sem graça, disse que vinha frequentando o espaço fazia um tempo e 
que estava sendo importante conhecer o bairro, que eu ainda não conhecia. Eu voltei pra casa ainda sob efeito dessa pergunta, alheia aos tombos do busu, aos ambulantes que entram vendendo algo, eu olhava pela janela a paisagem se transformar e como essa transformação tem total ligação com a pergunta que ele me fez. Era pro outro lado da cidade que eu voltava, pra "parte alta", limpa, de prédios altos. Inclusive eu me apresso em sair de lá quando começa à anoitecer,

porque eu tenho medo, esse sentimento ainda não desapareceu por completo, eu tenho medo do bairro que ele mora. Eu vou ao bairro, acho lindo o trabalho que eles fazem, tento colaborar, mas isso nunca vai mudar por completo a realidade, muito dificilmente deixará de ser o bairro onde quem vai pra ser turista não quer morar. (Diário de campo, 02 de agosto de 2016).

O questionamento feito por esse jovem, reflete várias questões sobre o bairro, como a falta de infraestrutura (o que inclui dificuldades de acesso à rede de esgoto e água potável, bem como à moradia adequada) e $\mathrm{o}$ alto índice de violência.

Nos termos do senso corrente, o bairro Uruguai seria uma comunidade considerada "carente".

Eu só consegui me dar conta do quanto é contraditório e preconceituoso esse termo depois de um tempo frequentando a Rede. Depois de conhecer e ver como a Rede se organiza na comunidade, como continuar a dizer que essas pessoas são 'carentes'? (Diário de campo, 15 de agosto de 2016).

Concluí, como efeito da experiência vivida, que a utilização desse termo apenas reafirma uma visão estigmatizada para com o lugar e para com as pessoas, que não são "carentes", mas impedidas de acessar oportunidades e direitos por questões históricas, culturais e sociais, que tendem a determinar as formas de ocupação dos centros urbanos no Brasil.

A Rede surgiu em agosto de 2004, pela iniciativa de 30 adolescentes e jovens participantes de uma Associação de Moradores do bairro. O grupo era formado por alunos de uma escola que não oferecia Ensino Médio, e que por isso teriam que sair para estudar em outras escolas. Resistentes, abraçaram a proposta de uma professora em criar um grupo para discutir temáticas sociais, e com isso manter a rede de relações criadas entre colegas, professoras e o território.

Em termos jurídicos, a Rede é uma organização da sociedade civil, sem fins lucrativos, e se mantém através do apoio da Visão Mundial5, e de uma associação de moradores, contando ainda para sua sustentabilidade com o financiamento captado através de editais para viabilizar projetos e atividades, como festas e bingos. Para cumprir sua finalidade de mobilizar as juventudes do território no sentido de que os(as) jovens (re)conheçam seus direitos e saibam como acessá-los, a Rede se articula com toda a Península de Itapagipe, interagindo com diversos grupos culturais, associações de bairro, escolas comunitárias, municipais e estaduais, uma casa de oração do bairro, uma base comunitária da polícia militar do bairro e a prefeitura-bairro; além da já citada Visão Mundial, da Fundação Cultural do Governo da Bahia e da Secretaria de Cultura do Estado da Bahia (SECULT).

A Rede ocupa o Espaço Cultural Alagados, funcionando como um grupo residente e nos moldes de gestão compartilhada. Devido ao Espaço Cultural funcionar de forma precária, a Rede passou a desenvolver suas atividades no local, contribuindo com o cumprimento de sua finalidade e ampliando a participação e a presença da comunidade. A SECULT, reconhecendo o valor do trabalho desenvolvido, permitiu que a Rede passasse a grupo residente e continuasse a promover acolhimento, cuidado, espaços de expressão e encaminhamentos necessários para aqueles jovens. Ressalte-se que a gestora do Espaço Cultural é também a coordenadora pedagógica da Rede.

Importante salientar que a Rede de jovens se organiza em diversos níveis, na busca por um cuidado integral para todos que dela fazem parte, assim como a ideia de Redes em saúde, que organiza seus arranjos em diferentes densidades, de forma articulada e visando a efetivação da integralidade no cuidado. Nesse sentido, a rede se aproxima em muitos aspectos da Rede de Atenção Psicossocial (RAPS).

\footnotetext{
${ }^{5}$ Organização cristã de desenvolvimento e resposta às situações de emergência. Está no Brasil desde 1975 atuando através de programas e projetos nas áreas de proteção, educação, advocacy e emergência, priorizando crianças e adolescentes que vivem em situação de vulnerabilidades diversas.
} 
Entre as ações e projetos desenvolvidos estão: uma rádio comunitária, que além das músicas, divulga novidades sobre seu trabalho; oficinas de estamparia, dança, teatro, informática, estética afro, bijuterias, artesanato e educação ambiental para crianças, adolescentes e jovens, bem como para suas famílias, algumas delas realizadas em articulação com as instituições parceiras; rodas de diálogos, é um espaço de encontro e expressão, onde adolescentes e jovens discutem vários temas ligados às juventudes, questões sociais e políticas numa perspectiva de formação cidadã e ações culturais com intuito formativo e estético; Terças culturais, é um evento temático, voltado para a comunidade que ocorre na última terça de cada mês, onde acontecem apresentações dos grupos de dança e teatro da própria rede, além de grupos convidados; Grupo de palhaçaria criado pelos jovens, com o intuito de interagir com as crianças da comunidade; Corredor da poesia, um espaço para que os jovens possam se expressar recitando poesias de própria autoria ou de poetas com os quais se identifica; Curso de mídias digitais, como fotografia, montagem e finalização de vídeo; E o turismo comunitário, desenvolvido em parceria com uma Associação local, com turistas brasileiros e estrangeiros.

Todas as atividades parecem ser de grande valor para a comunidade e "um compromisso pelo qual cada pessoa, renunciando à anarquia das pulsões individuais, contribui com sua cota para a vida coletiva" (Certeau, Giard \& Mayol, 2005, p. 39).

\section{O fazer}

"Participar da roda de diálogos já muda muita coisa pra mim, eu não estaria mais só na faculdade assistindo aula, começaria a fazer algo, sairia desse lugar passivo de aluno" (Diário de campo, 16 de abril de 2016).

No período em que estive participando da Rede, as atividades desenvolvidas aconteciam em conjunto com os educadores sociais, que ela dispõe e que desenvolvem semanalmente rodas de diálogos, com jovens que tem entre 15 e 24 anos

"Nesses dois semestres participando das atividades da Rede, percebo como as vivências têm acontecido em mim intensamente. Muitas coisas mudaram na minha vida pessoal e de estudante/profissional" (Diário de campo, 22 de novembro de 2016).
Nas rodas de diálogos, temáticas diversas eram discutidas, como política, cidadania, relações de gênero, extermínio da juventude negra, entre outras. Além disso, os(as) jovens eram preparados(as) para serem selecionados(as) no programa Primeiro Emprego, desenvolvido através de parcerias com outros grupos e empresas. A quantidade de jovens nas rodas variava entre 15 e 40 participantes.

As minhas participações nessas rodas, em alguns momentos, eram na condição de propor atividades, dinâmicas e discussões, identificando no grupo as temáticas de interesse para serem abordadas e em outras participando do que era proposto pelos Educadores Sociais. Algumas atividades, eram mediadas pela coordenadora pedagógica, visto fazerem parte de um calendário anual previamente concebido, ainda que flexível. Essas atividades pré-estabelecidas no calendário faziam par com datas comemoradas nacionalmente, como por exemplo, o dia 18 de maio: Dia de combate ao abuso e à exploração sexual de crianças e adolescentes. Portanto, todas as rodas de diálogos do mês de maio tratariam dessa temática, utilizando diversas linguagens: filmes, documentários, curtas, reportagens, dados estatísticos etc.

Participar diretamente das atividades propostas pela Rede não foi um processo fácil, pois demandou flexibilidade e capacidade de se adaptar e contextualizar o planejamento, evitando o risco de "achar que ‘nada foi produzido' por não haver saído como planejado" (Bocco \& Lazzarotto, 2004, p.43).

Hoje, pela primeira vez, pude propor a discussão da roda de diálogos e mediar essa discussão. Mas foi um fracasso, a conversa não fluía, a galera que geralmente falava tanto, não participava. E eu sem saber o que fazer, o que propor, o que improvisar. $O$ grupo realmente não aderiu. E eu me dei conta de que precisava me aproximar mais deles, daquele universo, daquela linguagem e pra isso eu decidi passar um tempo no espaço, quando as rodas se encerrarem, pra conversar com eles informalmente, ficar por ali circulando (Diário de campo, 17 de maio de 2016).

Entretanto, estar no lugar informal e "sair da noção disciplinar de tarefas a serem cumpridas" (Bocco \& Lazzarotto, 2004, p.43), não se configurou como uma tarefa fácil, mas necessária, para que a possibilidade de viver uma experiência não fosse destruída. 
A convivência informal é muito sutil, e desencobre fortemente as diversidades econômicas, sociais, raciais e culturais. É atravessar e arriscar conviver com o desconhecido e "mergulhar em profundidade para se chegar à inacessível proximidade" (Espinheira, 2008, p. 79). Para ilustrar, segue algo que registrei em meu diário de campo à época:

Hoje, algo me causou incômodo, embora eu saiba que estou num contexto de pessoas negras, eu não imaginei que o fato de ser branca marcasse um lugar, já que a Rede é tão articulada e tão receptiva. Mas um dos adolescentes de gastação com minha cara perguntou se minha mãe me deu banho de Qboa (sic) quando eu era criança. Isso gerou muitos risos, inclusive entre os educadores. Eu não respondi, não sabia o que responder (Diário de campo, 03 de maio de 2016).

Foi uma dificuldade estar (ser colocada) neste lugar de não pertencimento e sequer conseguir falar sobre ele, por saber que esses discursos no âmbito das relações raciais são sempre muito calorosos e as pessoas, mesmo estando no curso de Psicologia, têm posicionamentos enviesados pela militância e irredutíveis ao diálogo que não obedeça à lógica por eles defendida.

Esses aspectos despertaram em mim reflexões sobre futuras atuações profissionais em contextos públicos e comunitários, e de como ser branca, e ter estudado em uma faculdade particular, colocam o(a) profissional em um lugar de privilégio que o(a) faz ser olhado de uma outra maneira, gerando questionamentos sobre a legitimidade da sua presença nesses espaços.

'Hum, da Bahiana...' E eu senti um tom de ironia na fala, que seguiu de risadas entre alguns do grupo. $E$ ali eu pude perceber que estar em uma instituição particular e tida como 'de elite', tem um significado, $e$ que as pessoas irão me olhar de outro jeito por isso (Diário de campo, 21 de março de 2016).

\section{Considerações finais}

Bondía (2002) alerta para a dificuldade cada vez maior em viver uma experiência, sendo uma de suas causas a falta de tempo. Atualmente as vivências seriam tão instantâneas que as pessoas andariam correndo contra o tempo, impedidas de viver os acontecimentos, os desvios, os encontros, e desejando sempre a novidade, que não duraria mais que um instante. Permanecer na Rede durante três semestres foi a possibilidade de fazer o inverso e, de fato, vivenciar uma experiência que mudou meu (per)curso. Participar das atividades e conviver com o grupo foi desacostumar o olhar da cegueira de ver sempre o mesmo.

Conforme Senne (2005) alerta que haveria na atualidade um movimento de expansão na atuação do Psicólogo, para além dos contextos clínico, educacional e industrial, e aproximando-se, por exemplo, do trabalho em rede, onde o(a) psicólogo(a) atuaria em funções estratégicas e políticas. Ou seja, apresentase a compreensão de se estar demandando do(a) psicólogo(a) uma atuação diversa das "clássicas", onde em um mesmo contexto, o(a) psicólogo(a) se colocaria em diversas posições, colocando-se sempre como aquele(a) que não sabe, ocupando espaços de escuta e mediação.

Colocar-se disponível para aprender com os jovens da Rede - do planejamento de uma oficina ao manejo de grupo - e nesse processo perceber nas críticas e situações difíceis possibilidades de aprendizagem, foi um desafio. O corpo foi sendo sensibilizado e acontecimentos corriqueiros se tornaram relevantes.

Em uma das idas ao coletivo, acabei saindo mais tarde que de costume. Já era noite, e no ônibus, por muito tempo, estivemos somente eu e o motorista. Até que em um dos últimos pontos antes de chegar à Estação da Lapa entrou um menino vendendo amendoim. Ele estava só. Não pude conter a minha curiosidade e puxei conversa. Ele então me disse como se chamava, que tinha 10 anos e residia no bairro de São Gonçalo, em Salvador. É um dos mais jovens de uma família de oito filhos. Junto com os pais e os irmãos ele anda pela cidade vendendo amendoim e doces. Perguntei se ele não tinha medo. Ele riu de um jeito acanhado e respondeu 'Tenho não'. Sua rotina é todos os dias a mesma: pela manhã vai à escola, depois em casa faz suas atividades escolares e pelas $15 \mathrm{~h}$ sai pra vender, voltando pra casa lá pelas $21 \mathrm{~h}, 22 \mathrm{~h}$. Eu fui pra casa pensando o que a Rede poderia fazer por ele. 'Quais as transformações que poderia ter a vida dele, se tivesse a oportunidade de estar em um espaço como o que é proporcionado pela Rede?' (Diário de Campo 07 de fevereiro de 2017). 
A forma de falar e as palavras usadas, também passaram a ser uma questão. Fui-me dando conta de que elas poderiam aproximar ou distanciar, incluir ou excluir, principalmente por ser um grupo de jovens, onde as gírias estão muito presentes. Compreender a necessidade de se deslocar das funções e se colocar disponível para estar com o outro, informalmente, estabelecendo uma relação de troca, ouvindo a história do outro e podendo colocar a sua, pareceu-me fundamental para firmar a minha legitimidade e, quem sabe, seria algo a considerar desde o lugar instituído para o(a) psicólogo(a) em minhas atuações futuras enquanto profissional - algo aparentemente distinto da suposta "distância" que se espera do(a) psicólogo(a) em seus contextos de atuação.

Fui-me tornando sensível à importância de conhecer as pessoas e o território, sensibilizada por uma realidade diferente, à qual não estava acostumada. $\mathrm{E}$ neste processo foi possível perceber o quanto a psicologia é uma ciência que precisa ampliar seu entendimento quanto ao que considera o seu reduto clínico, e pensar e atuar de um lugar social e político a céu aberto, junto à população, mas também, e principalmente, junto àquelas pessoas que têm seus direitos violados ou negados em alguma qualquer medida.

Constatei que questões relevantes, como a violação de direitos, a impossibilidade de acesso a serviços e determinados espaços, também são assuntos "de psicólogo(a)", e reconheci a superação das desigualdades sociais como uma forma de cuidado em saúde, vislumbrando as dimensões política, cultural e social da profissão que componentes curriculares de "psicologia social" não ensinaram, e só foram evidenciadas no contexto da experiência relatada.

Compreender a importância e a necessidade de manutenção de espaços e grupos como a Rede foi fundamental, pensando nas marcas históricas de um país como o Brasil, que viveu por mais de 20 anos uma Ditadura Militar e tem nesse momento sua democracia ameaçada. Concluí pela necessidade de lutar pela manutenção de espaços como a Rede, que oportunizam a discussão a respeito de muitos temas cotidianos relevantes e que, através de suas atividades culturais e ações políticas, torna-se mais um lugar de resistência.
Concluí ainda que o difícil papel do(a) psicólogo(a) é ser o que faz "levantamento de dados" ao tempo em que se deixa atravessar pelo que escuta, cheira, saboreia, vê e sente. E somente assim poderá dizer que viveu uma experiência, um Acontecimento: "querer o acontecimento significa [...] querer alguma coisa no que acontece, alguma coisa a vir de conformidade ao que acontece" (Deleuze, 1992, apud Andrade, 2018, p. 9). O difícil papel do(a) psicólogo(a) é dispor o corpo para os atravessamentos.

Portanto, uma formação em psicologia que considere o aprendizado também através de um saber sensível, poderá contribuir como preparação do corpo para estar disponível ao encontro, superando o processo de embotamento ao qual somos frequentemente expostos(as).

\section{Contribuições dos autores}

Bastos SGS participou da concepção, delineamento, análise e redação do artigo científico. Azevedo FGS participou da concepção, delineamento, orientação e revisão do artigo científico.

\section{Conflitos de interesses}

Nenhum conflito financeiro, legal ou político envolvendo terceiros (governo, empresas e fundações privadas, etc.) foi declarado para nenhum aspecto do trabalho submetido (incluindo, mas não se limitando a subvenções e financiamentos, participação em conselho consultivo, desenho de estudo, preparação de manuscrito, análise estatística, etc.).

\section{Referências}

Andrade, E. P. (2018). A Filosofia do Acontecimento em Deleuze. O Maguezal- Revista de Filosofia, 1(2) 6-18. https://seer.ufs.br/ index.php/omanguezal/article/view/9403

Bocco, F., \& Lazzarotto, G. D. R. (2004). (Infr) atores juvenis: artesãos da análise. Psicologia \& Sociedade, 16(2), 37-46. https://dx.doi.org/10.1590/S0102-71822004000200006

Bondía, J. L. (2002). Notas sobre a experiência e o saber de experiência. Revista Brasileira de Educação, (19), 20-28. https://dx.doi.org/10.1590/S1413-24782002000100003 
Certeau, M., Giard, L., \& Mayol, P. (2005). A Invenção do Cotidiano: 2. Morar, Cozinhar (6a ed.). Editora Vozes.

Conselho Federal de Psicologia (2018). Repensar a formação em Psicologia. Conselho Federal de Psicologia. https://site.cfp. org.br/repensar-a-formacao-em-psicologia/

Duarte Júnior, J. F. (2001). O sentido dos sentidos: a educação (do) sensível (3a ed.). Criar Edições.

Espinheira, G. (2008). Metodologia e prática do trabalho em comunidade. EDUFBA.

Macedo, R. S. (2016). A Pesquisa e o Acontecimento: compreender situações, experiências e saberes acontecimentais. EDUFBA

Nascimento, M. L., Manzini, J. M., \& Bocco, F. (2006). Reinventando as práticas psi. Psicologia \& Sociedade, 18(1), 15-20. https:// dx.doi.org/10.1590/S0102-71822006000100003
Pessoa, F. (1914/2016). O Guardador de Rebanhos. Globus Editora.

Portaria $n^{\circ}$ 4.279, de 30 de dezembro de 2010. Diário Oficial da União, Brasília-DF, Seção 1, p. 89, 31 dez. 2010. Estabelece diretrizes para a organização da Rede de Atenção à Saúde no âmbito do Sistema Único de Saúde (SUS). http://portal. saude.gov.br/portal/arquivos/pdf/portaria4279_docredes. pdf Acesso em: 10 agosto. 2018

Ramos, C., \& Carvalho, J. E. C. (2008). Espaço e subjetividade: formação e intervenção em psicologia comunitária. Psicologia \& Sociedade, 20(2), 174-180. https://dx.doi. org/10.1590/S0102-71822008000200004

Senne, W. (2005). O que estarão fazendo os psicólogos? In Senne, W. Psicologia e psicodiagnóstico: bases epistemológicas. Vozes. 